\title{
Az Bilinen Bir Konu ‘'́diyopatik Kronik Pelvik Ağrı’: Bir Olgu Sunumu
}

\author{
Pınar SIVRIKAYA, Çiçek HOCAOĞLU
}

Recep Tayyip Erdoğan Üniversitesi Tıp Fakültesi, Psikiyatri Anabilim Dalı, Rize.

\section{ÖZET}

Kronik pelvik ağrı (KPA) özellikle üreme çağındaki kadınları etkileyen önemli sağlık sorunlarından biridir. Jinekolojik, ürolojik, nörolojik, gastrointestinal, kas-iskelet sistemi gibi çok sayıda sistemden kaynaklanabilen KPA'nın ayıııcı tanısında güçlükler yaşanabilir. Tibben açıklanamayan idiyopatik kronik pelvik ağrı (IKPA) psikolojik nedenlere bağlı ortaya çıkabilir. Oldukça sık rastlanmasına rağmen IKKPA'nın etiyolojisi, klinik görünümü, seyri ve tedavi yaklaşımı ile ilgili bilgiler kısıtlıdır. Bu çalışmada depresif yakınmalarla başvuran ve İKPA tanısı ile izlenen 43 yaşındaki kadın olgu literatür bulguları ışığında sunulmuştur. Hastanın İKPA yakınmaları ile sık sık hastane başvurularının olması dikkat çekicidir. Klinisyenlerin tıbben açıklanmayan IKXPA’nın psikiyatrik yönü konusunda duyarlı olmaları önemlidir.

Anahtar Kelimeler: İdiyopatik Kronik Pelvik Ağrı. Tanı. Tedavi.

\section{A Little Known Topic 'Idiopathic Chronic Pelvic Pain': A Case Report}

\begin{abstract}
Chronic pelvic pain (CPP) is one of the most important health problems affecting women of reproductive age. There may be difficulties in the differential diagnosis of CPP, which may arise from many systems such as gynecological, urological, neurological, gastrointestinal and musculoskeletal systems. Medically unexplained idiopathic chronic pelvic pain (ICPP) may occur due to psychological reasons. Although it is quite common, information about the etiology, clinical appearance, course and treatment approach of ICPP is limited. In this study, a 43year-old female patient who presented with depressive complaints and was followed up with a diagnosis of ICPA was presented in the light of literature findings. It is noteworthy that the patient has frequent hospital admissions with ICPA complaints.It is important for clinicians to be sensitive about the psychiatric aspect of medically unexplained ICPA.
\end{abstract}

Key Words: Idiopathic Chronic pelvic pain. Diagnosis. Treatment.

İdiyopatik kronik pelvik ağrı (IKPA), en az 6 ay süreyle devam eden, tıbben açıklanamayan, döngüsel olmayan pelvik bölgede ağrı, rahatsızlık hissi ile devam eden bir durum olarak tanımlanır., ${ }^{1,2}$ DSM-5'e göre "Ağrının Baskın Olması ile Giden Bedensel Belirti Bozuklukları" içerisinde sınıflandırılmıştır. Zaman zaman belirgin ağrn ile tariflenemeyen huzursuzluk hissi, karıncanlanma uyuşma şikayetleri de görülebilmektedir. Kişi pelvik ağrının yanı sıra fibro-

Geliş Tarihi: 19.Eylül.2021

Kabul Tarihi: 08.Kasım.2021

\section{Dr. Çiçek HOCAOĞLU}

Recep Tayyip Erdoğan Üniversitesi

Tıp Fakültesi Psikiyatri Anabilim Dal,

Rize.

Tel: 046421304 91-1506

E-posta: cicekh@gmail.com

Yazarların ORCID Bilgileri:

PInar SIVRIKAYA: 0000-0002-4954-5365

Çiçek HOCAOĞLU: 0000-0001-6613-4317 miyalji, migren, irritabl barsak sendromu, cinsel istek kaybı gibi pek çok durumu da birlikte yaşayabilir. ${ }^{4,5}$ Hayat kalitesinde bozulmaya neden olan bu durum nedeniyle kişiler pek çok kez hastaneye başvurmaktadır. Kan tetkiklerinin yanı sıra endoskopi, kolonoskopi ve ultrasongorafi gibi yapılan pek çok inceleme ve fizik muayeneye rağmen, tıbbi etiyoloji tespit edilemeyen pelvik bölgede ağrı ile seyreden tablo IKPA olarak tanımlanmaktadır. ${ }^{6}$ Etiyolojide yer alan nedenler psikososyal açıdan incelendiğinde siklıkla altta yatan depresif dönem, anksiyete bozuklukları, travma sonrası stres bozukluğu, fiziksel/cinsel travma öyküsü, partner ile yaşanan problemler olabilir. Hastalığın tedavisinde biyopsikososyal yaklaşım önem kazanmaktadır. ${ }^{7}$ Farmakolojik tedavinin yanı sıra bilişsel davranış̧ı terapi ve fizyoterapi uygulamalarından da fayda sağlandığını bildiren çalışmalar bulunmaktadır. ${ }^{8,9}$ IKPA, özellikle kadınlarda oldukça sık rastlanmasına rağmen az bilinen bir konudur. Etiyolojisi, klinik görünümü, seyri ve tedavi yaklaşımı ile ilgili bilgiler kisıtlıdır.

$\mathrm{Bu}$ çalışmada psikiyatri polikliniğimize depresif yakınmalarla başvuran, takipleri sırasında IKPA belirti- 


\section{P. Sivrikaya ve Ç. Hocaoğlu}

leri izlenen kadın hastanın klinik bulguları konu ile ilgili diğer çalışmalarının sonuçları ile tartışılarak mevcut literatüre katkı sunulması amaçlanmıştır.

\section{Olgu Sunumu}

Kırk üç yaşında kadın hasta, evli, 4 çocuk annesi, ortaokul mezunu, ev hanımı ailesi ile birlikte yaşıyor.

Keyifsizlik, isteksizlik, iş yapamama, mutsuzluk, hayattan zevk alamama, karın ağrısı, iştahsızlık, uyku düzensizliği ve bayılma yakınmaları ile eşi refakatinde başvuran hasta psikiyatri polikliniğimizde değerlendirildi.

İlk yakınmaları on üç yıl önce iştahsızlık, kilo kaybı, halsizlik ve isteksizlik olarak başlayan hastanın o dönemde tekrarlayan bayılmaları nedeni ile s1k s1k hastane başvurusunun olduğu belirtildi. Bu bayılmalar sırasında çevreden gelen sesleri duyabildiğini, fakat yanıt veremediğini belirten hasta bu sürecin eşinin hem çalışıp hem üniversite okuması nedeniyle oldukça yoğun olduğu ve ailesine yeterince vakit ayıramadığ bir döneme denk geldiğini söyledi. Yakınmalarının devam etmesi üzerine psikiyatri hekimine başvuran hastaya paroksetin $20 \mathrm{mg} /$ gün başlandığı, tedaviden fayda gördüğü, şikayetlerinin gerilemesi üzerine tedaviyi yarıda bıraktığı öğrenildi. Tedaviyi kestikten bir süre sonra şikayetlerinin tekrarlaması üzerine tekrar aynı tedaviyi kullanması önerilen hasta; yaklaşık 3 yıl daha ilacını kullanıp ardından tedaviyi tekrar bıraktığını ifade etti. Dört y1l önce gerçekleşen planlı olmayan bir gebelik öyküsü mevcuttu. Gebeliği süresince eşinin kendisine ilgisinin azaldığını hissettiğini ve sonrasında eşinin kendisini aldattığını öğrendiğini belirtti. Aynı dönemde 18 yaşındaki kızının da kendisinin onaylamadığı bir kişi ile evlenmesinden etkilendiğini ifade etti. Hasta son 4 yıldır bu olaylar sonrası kayg1, üzüntü, hayal kırıklı̆̆ı, güven kaybı duygularını takiben tekrar iştahsızlık ve karın ağrısı şikayetlerinin başladığını söyledi. Aynı zamanda genital bölgesinde uyuşukluk, karıncalanma hissi ve cinsel isteksizlik yakınmaları olduğunu belirtti. Bu nedenle genel cerrahi ve jinekoloji polikliniklerine başvurduğunu; genel cerrahi tarafından kindusuni endoskopi uygulandığını ifade etti. Fakat yapılan endoskopisinde, kan tetkiklerinde, fizik ve jinekolojik muayenelerinde şikayetlerini açıklayacak tıbbi neden bulunamadığını belirtti. Yapılan tetkiklere rağmen patolojik bir bulgu elde edilememesi üzerine psikiyatri polikliniğine başvuran hasta tarafimızca değerlendirildi.

\section{$\ddot{O} z$ geçmiş}

Normal doğum ile dünyaya geldiği, annesinin gebelik sırasında her hangi bir hastalığı olmadı̆̆ 1 , istenen bir bebek olduğu belirtildi. Zamanında yürüdüğü, konuştuğu, tuvalet alışkanlığı edindiği öğrenildi. Annesi ilkokul mezunu, anne ve babası hayatta ve sağlıklı, kendisinden büyük iki ağabeyi var. Anne ve babasının görücü usulü evlendiği, çok sık tartıştıkları fakat her şeyi birlikte yaptıkları, birbirlerine çok düşkün oldukları öğrenildi. Evin küçüğü ve kız çocuk olduğu için kendisini kayırdıklarını, tek çocuk gibi yetiştirdiklerini, ağabeylerinin bu durumdan mutsuz olduğunu ifade etti. Çocukken kendisini iyi huylu, çok hassas olarak tanımladı. Beş yaşında okula başladığını, okuma-yazma öğrendiğini, cesaretli, çalışkan bir öğrenci olduğunu belirtti. Sınıfta arkadaşlarından daha ön planda bulunmak isteği olduğunu ifade etti. On üç yaşında adet gördüğünü, ergenlik dönemi ile ilgili konuları mahalledeki ablaların anlattıklarından öğrendiğini, bu süreci büyümek olarak algıladığ görmeye başladığında her hangi bir korku-endişe yaşamadığı belirtti. Fakat çocukken anne-babasının cinsel ilişkilerine tanık olduğunu ve o zamanlar onların çok pis, kötü olduğunu düşündüğünü ifade etti. $\mathrm{Bu}$ konuda öfke, hatta kin duyduğunu, geceleri annesi banyo yaptığında bu sebeple çok sinirlendiğini ve annesinin ağlayıp üzüldüğünü belirtti. On dokuz yaşındayken, eşiyle akrabalar vasıtasıyla tanıştığını ve severek evlendiğini belirtti. Eşi 47 yaşında, memur olarak çalışıyor. Eşini iyi bir insan, iyi bir baba, yumuşak başlı, güzel huylu, insancıl biri olarak tanımlad1. Fakat gereksiz sert tepkileri ve ani çıkışları olmasından rahatsızlık duyduğunu belirtti. Eşinin çok sosyal biri olduğunu, genel olarak eşi ile karakter olarak çok farklı ve uyumsuz olduklarını düşündüğünü belirtti. Evlendikten ancak bir ay sonra cinsel birliktelik yaşayabildiklerini, ilk cinsel birliktelikleri sırasında ürktüğünü, beklediği gibi olmadığını, kendisini çok kastığı için haz alamadığını ifade etti. Sigara, alkol ve diğer psikoaktif madde kullanım öyküsü olmayan hastanın, hastalanmadan önce dişa dönük, yardımsever, titiz, kuruntulu, mükemmeliyetçi bir kişiliğe sahip olduğu öğrenildi. Nörolojik muayene ve diğer sistem muayeneleri ile hemogram, endokrin (açlik kan şekeri, tiroid fonksiyon testleri), rutin biyokimyasal tetkiklerinde patolojik bulgu saptanmadi.

Ruhsal Durum Muayenesi: Yaşında görünümde, giyimi sosyoekonomik düzeyi ile uyumlu, özbakımı iyiydi. Görüşmeye istekli, göz teması kuran hastanın konuşma hızı ve miktarı, ses tonu normaldi. Duygudurumu çökkün, affekti duydurumu ile uyumluydu. Zeka düzeyi klinik olarak normal düzeyde, bellek fonksiyonlar1 korunmuştu. Algılamada psikopatolojik bulgu tespit edilmedi. Gerçeği değerlendirme, soyut düşünme yetisi ve yargılaması olağandı. Düşünce süreci ve çağrışımları düzenli, amaca yönelikti. Düşünce içeriğinde eşinin kendisini aldatmasına yönelik yaşamış olduğu güvensizlik duyguları, kendisini değersiz hissetmesi ön plandaydı. Ayrıca, yaşadığı fiziksel semptomlar nedeniyle de kaygılıydı. Benlik saygısı azalmıştı. Kısmi psiko-motor retardasyon tabloya eşlik ediyordu. 


\section{Kronik Pelvik Ağrı}

\section{Klinik Seyir}

Psikiyatrik değerlendirme sonrası hastaya DSM-5'e göre Major Depresif Bozukluk (MDD) tanısı ile paroksetin $20 \mathrm{mg} /$ gün tedavisi başlandı ve bilişsel davranışçı terapi (BDT) uygulandı. İlerleyen görüşmelerde uzun süredir devam eden pelvik ağrısı nedeni ile hastaya DSM-5'e göre "Ağrının Baskın Olması ile Giden Bedensel Belirti Bozuklukları" tanısı konuldu. Hamilton Depresyon Değerlendirme Ölçeği'nden (HADÖ) 12, Toronto Aleksitimi Ölçeği-20 (TAS-20), TAS(A): Duyguları tanıma zorluğu: 20, TAS (B): Duyguları İfade Etme Zorluğu: 15, TAS (C): Dişavuruk Düşünce:17, genel toplam 52 puan olarak değerlendirilmiştir. Poliklinik kontrolünde değerlendirilen hastanın tedavisini düzenli şekilde kullandığı, depresif yakınmalarının azaldığı, bir yıl süreyle düzenli olarak takip edilen hastanın semptomlarında gerileme olduğu, pelvik ağrısının, cinsel isteksizliğinin azaldığı öğrenildi. Ölçeklerden alınan puanlar (HADÖ: 3, TAS-20: 27) da bu durumu destekler nitelikteydi. Olgu sunumu olarak bilimsel amaçlı kimliği gizli olacak şekilde bilimsel bir dergide yayınlanmak üzere hastadan yazılı onamı alındı.

\section{Tartışma ve Sonuç}

Ağr1, bedenin herhangi bir bölgesinden kaynaklanan ve etiyolojisi çok farklı nedene bağlı olan hoş olmayan bir duyumsama durumu olarak tanımlanabilir. ${ }^{10}$ Doku harabiyetine de neden olabilen ağrı yaşantısı, kişinin yaşamını olumsuz olarak etkiler. Çok sayıda ağrı türü hastaların tıbbi başvurularının başında yer alır. Özellikle uzun süredir devam eden ve tedaviye yanıtı sınır11 tıbben açıklanmayan kronik ağrı hastaların yaşam kalitesini olumsuz etkilemektedir. ${ }^{11}$ Çünkü ağrının ortaya çıkışı ve şiddeti kişinin geçmişindeki öznel deneyimleri ve psikolojik durumu ile ilgili olabilir. Somatizasyonun, özgül bir belirti olmamakla birlikte, hastalık olarak değerlendirmek yerine yaşanan duygusal tabloyu bedensel yakınmalar eşliğinde algılamak ve iletmek olarak tanımlanması daha uygun olur. O1gumuzun aleksitimik yapısı ve stresli yaşam olayları göz önünde bulundurulduğunda pelvik ağrıya neden olabilecek psikososyal nedenler açısından literatür ile uyum göstermektedir. ${ }^{12}$ Yine olgumuzda IKKPA'ya eşlik eden cinsel isteksizlik, kilo kaybı, iştahsızlık ve bayılma şikayetlerinin bulunması da psikiyatrik tabloyu destekler niteliktedir. Kişilerin tedavi arayışları; çoklu hastane başvuruları nedeniyle sağlık harcamalarını da beraberinde getirmektedir. ${ }^{13}$ Bununla birlikte hastalığın tanınmadığı ve uygun tedavi yaklaşımının benimsenmediği durumlarda hastanın tedaviye olan inancını azaltarak tedavi uyumunu bozabilmektedir. Hastamızın genel cerrahi ve jinekoloji polikliniklerine sık başvurularının olması, endoskopi-kolonoskopi dahil olmak üzere tetkiklerinin yapılmış fakat tıbben açıklanabilen bir neden bulunamamış olması da bu duruma ışık tutar niteliktedir. Hastamıza MDD tanısı ile paroksetin $20 \mathrm{mg} /$ gün tedavisi başlanmıştır. Paroksetinin cinsel işlev üzerindeki bilinen yan etkilerine rağmen, hastamızın tedaviden fayda görmüş olması altta yatan patolojinin depresyon ile ilişkili olabileceğini düşündürmektedir.

Sonuç olarak, İKPA kişinin hayat kalitesinde ve işlevselliğinde bozulma ile giden, sık rastlanmasına rağmen az bilinen bir konu olması nedeniyle önem kazanmaktadır. Ağrının tıbbi sebepleri sıklıkla saptanamaz ise, başarılı şekilde tedavi edilmesini güçleştirir. İKPA'nın tıbben açıklamadığı durumlarda psikopatolojik nedenleri iyi sorgulamak gerekir. Oluş nedenleri, epidemiyolojisi, diğer ruhsal bozukluklarla ilişkisi ve tedavi yaklaşımları tam olarak bilinmeyen IKPA'nın daha iyi anlaşılabilmesine ihtiyaç vardır. Çalışmamızın bu konuda ileride yapılacak çalışmalara katkı sunacağı inancındayız.

\section{Etik Kurul Onay Bilgisi:}

Olgu bildirimi olduğundan dolayı Etik Kurul onayına gerek yoktur. Hasta onamı alınmışıır.

Araştırmacı Katkı Beyanı: Fikir ve tasarım: Ç.H.; Veri toplama ve işleme: P.S., Ç.H.; Analiz ve verilerin yorumlanması: P.S.; Makalenin önemli bölümlerinin yazılması: P.S, Ç.H

Destek ve Teşekkür Beyanı: Makale çalışmalarına finansal destek sağlayan yoktur.

Çıkar Çatışması Beyanı: Makale yazarlarının çıkar çatışması beyanı yoktur.

\section{Kaynaklar}

1. 1.Speer LM, Mushkbar S, Erbele T. Chronic pelvic pain in women. Am Fam Physician. 2016;93(5):380-387.

2. Stein SL. Chronic pelvic pain. Gastroenterol Clin North Am. 2013;42(4):785-800.

3. American Psychiatric Association (APA). (2013). Diagnostic and Statistical Manual of Mental Disorders (DSM- 5®). American Psychiatric Pub

4. Wozniak S. Chronic pelvic pain. Ann Agric Environ Med. 2016 Jun 2;23(2):223-6.

5. Grinberg K, Sela Y, Nissanholtz-Gannot R. New Insights about Chronic Pelvic Pain Syndrome (CPPS). Int J Environ Res Public Health. 2020 Apr 26;17(9):3005.

6. Champaneria R, Shah L, Moss J, Gupta JK, Birch J, Middleton LJ, Daniels JP. The relationship between pelvic vein incompetence and chronic pelvic pain in women: systematic reviews of diagnosis and treatment effectiveness. Health Technol Assess. 2016; 20(5):1-108.

7. Till SR, As-Sanie S, Schrepf A. Psychology of Chronic Pelvic Pain: Prevalence, Neurobiological Vulnerabilities, and Treatment. Clin Obstet Gynecol. 2019 Mar;62(1):22-36.

8. Bonnema R, McNamara M, Harsh J, Hopkins E. Primary care management of chronic pelvic pain in women. Cleve Clin $\mathrm{J}$ Med. 2018 Mar;85(3):215-223.

9. Smith SE, Eckert JM. Interventional Pain Management and Female Pelvic Pain: Considerations for Diagnosis and Treatment. Semin Reprod Med. 2018 Mar;36(2):159-163. 
10. Fillingim RB, Loeser JD, Baron R, Edwards RR. Assessment of Chronic Pain: Domains, Methods, and Mechanisms. J Pain. 2016 Sep;17(9 Suppl):T10-20.

11. Hylands-White N, Duarte RV, Raphael JH. An overview of treatment approaches for chronic pain management. Rheumatol Int. 2017;37(1):29-42.

12. Wozniak S. Chronic pelvic pain. Ann Agric Environ Med. 2016; 2;23(2):223-6.
13. Gatchel RJ, McGeary DD, McGeary CA, Lippe B. Interdisciplinary chronic pain management: past, present, and future. Am Psychol. $2014 ; 69(2): 119-30$. 